\title{
Understanding and Measuring Adaptation Level Among Community-Dwelling Patients with Metabolic Syndrome: A Cross-Sectional Survey
}

This article was published in the following Dove Press journal: Patient Preference and Adherence

\author{
Xiyi Wang $\mathbb{D}^{\prime}$ \\ Jing Shao ${ }^{2}$ \\ Zhihong $\mathrm{Ye}\left(\mathbb{D}^{1,2}\right.$ \\ 'Department of Nursing, Zhejiang \\ University School of Medicine Sir Run \\ Run Shaw Hospital, Hangzhou, People's \\ Republic of China; ${ }^{2}$ Faculty of Nursing, \\ Zhejiang University School of Medicine, \\ Hangzhou, People's Republic of China
}

Correspondence: Zhihong Ye Department of Nursing, Zhejiang University School of Medicine Sir Run Run Shaw Hospital, Hangzhou, Zhejiang 310020, People's Republic of China

Tel +86-057I-86006608

Fax +86 057I-860448I7

Email yezh@zju.edu.cn
Purpose: This study aimed to translate the Roy adaptation model concept of adaptation level into measurable concepts when considering the health-related quality of life, social support, and self-efficacy of community-dwelling Chinese adults with metabolic syndrome. Patients and Methods: This was a descriptive cross-sectional study. Data were collected from 144 adults with metabolic syndrome in the suburban area of Hangzhou, China. Correlation analysis was performed to examine the relationships between environmental stimuli (sociodemographic characteristics), adaptation level (health-related quality of life and social support), and prerequisite of behavior (self-efficacy). Regression analysis was applied to test the effect of stimuli on adaptation level and their associations with behavior. Results: Adaptation level was potentially influenced by environmental stimuli and evaluated by the quality of life. Age and education level were related to physiological and psychological function. Besides, family income was related to physiological function. Thus, adaptation level may predict individuals' behavior towards illness management, with a percentage classification accuracy of $76.40 \%$. The vitality and social functioning of the quality of life were identified as significant correlates of self-efficacy.

Conclusion: Our findings demonstrate that individuals' internal and external resources should be considered when developing nursing interventions to improve patients' adaptation level. Future research should explore whether facilitating self-efficacy among communitydwelling adults with metabolic syndrome may positively influence an individual's adaptation process in health management.

Keywords: chronic illness, physiological adaptation, psychosocial adaptation, quality of life, social support, self-efficacy

\section{Introduction}

Metabolic syndrome (MetS) is a multi-component risk factor for cardiovascular diseases (CVD) and type 2 diabetes (T2DM). ${ }^{1}$ It is a cluster of an individual's cardiometabolic risk factors. ${ }^{1}$ Epidemiological studies have reported a high prevalence of MetS worldwide. $^{2-4}$ This is particularly so for patients with T2DM and hypertension. ${ }^{4,5}$ Given the poor prognosis and high all-cause mortality rate of CVD, early assessment of cardiometabolic risks and treatment is important. ${ }^{1,4}$ Identification of MetS is essential for healthcare professionals and patients to address the underlying lifestyle-related risk factors such as sedentary lifestyle, physical inactivity, smoking, and alcohol abuse. ${ }^{1,6}$

The impact of chronic illness on individual ability to adapt to daily life is determined by several aspects including physical, psychological, and social health 
status. $^{7-9}$ Assessing the capacity of an individual to cope with disease-specific problems is adequate for predicting self-management efficiency. Patients are unable to recognize the risks associated with the MetS thereby fail to initiate early behavioral modification. ${ }^{10,11}$ However, little is known about the characteristics of MetS patients and their ability to manage illness.

The adaptation level was adopted to assess how individuals prepare for illness control. This was achieved by describing the condition of life processes that are influenced by the demands of the situation and internal resources. $^{12}$ An individual's behavior weighted by environmental stimuli and adaptation level was identified as the adaptive or ineffective response. ${ }^{13,14}$ Pollock limited the measurement of adaptation level as the effectiveness of behavior from physiological and psychosocial domains in the context of chronic illness. ${ }^{13}$ The proposal was tested using five correlational studies. DeSanto-Madeya and Fawcett translated the concept of adaptation level into adjustment and tested the logical congruence in two studies on adaptation to life events. ${ }^{15}$ Literature reports indicate that the published instruments primarily measured either one adaptive mode or major coping and adaptation processing. ${ }^{16}$ So far, few empirical studies have explored the measurement and understanding of the adaptation level. However, preliminary findings have highlighted the possibilities of using adaptation level to describe an individual's abilities and responses to environmental stimuli.

Patient-reported outcomes are related to individual inner capacities and are applied to evaluate the effectiveness of nursing interventions, for example, the MetS in adults. ${ }^{11}$ Previous studies show that health-related quality of life (HRQOL) and social support affect individual responses and behaviors in health management. ${ }^{17-19}$ The HRQOL encompasses contentment with physical and psychosocial elements of the existing life circumstances of an individual. This captures the essence of adaptation level in representing the structures and functions of the life process. $^{20}$ Social support as a psychological factor occurs within the adaptation process and is important for effective self-management. ${ }^{21-23}$ The tools for measuring social support were used to characterize individual psychosocial adaptation. $^{23}$ Moreover, there is growing evidence that HRQOL and social support are positively associated with self-efficacy in disease control. ${ }^{17,24}$ Self-efficacy is a crucial precondition for individual confidence in selfmanagement and is an indicator of the clinical decisionmaking process. $^{21,25,26}$ Improved self-efficacy relies on measures for a community-based patient education program. ${ }^{17,26,27}$ In this way, the self-efficacy level can be used to estimate the ability of individuals to positively respond to changes that help understand the behavioral responses (classified as either adaptive or ineffective). From the adaptation perspective, the relationships between HRQOL, social support, and self-efficacy have not been assessed in MetS patients.

\section{Theoretical Framework}

Helson's adaptation-level theory describes humans as adaptive systems as they can adapt to altered environment conditions. ${ }^{14}$ As noted in the Middle-Range Theory of Adaptation to Chronic Illness (MRT-ACI), ${ }^{13}$ derived from the Roy Adaptation Model (RAM), defined concepts such as stimuli and adaptation level were implemented in the empirical study. Overall, the adaptation level is influenced by stimuli and can be operationalized as the inner capacity of an individual based on physiological and psychosocial aspects. This predicts the effectiveness of health behaviors. In this study, MetS patients perceived HRQOL and social support were defined as an adaptation level. Additionally, sociodemographic characteristics and lifestyle behaviors (identified as environmental stimuli) were considered essential personal factors promoting selfefficacy (regarded as a prerequisite of behavior) in disease management (Figure 1).

Therefore, this study aimed to [1] translate the concept of adaptation level into measurable variables within theoretical basis; [2] use the empirical indicators of HRQOL, social support, and self-efficacy to describe the adaptation level of MetS patients; and [3] to identify the potential associations among these concepts (environmental stimuli, adaptation level, and output).

\section{Patients and Methods Design}

This cross-sectional study was a secondary analysis of the baseline data from an interventional controlled study performed between May 2016 and October 2018.

\section{Participants}

Participants were recruited from four communities in the suburban area of Hangzhou, Zhejiang Province, China. Inclusive criteria included: adults (18 years and above), residents (living in the residual area for more than 1 year), diagnosed with type-2 diabetes mellitus (T2DM) or 


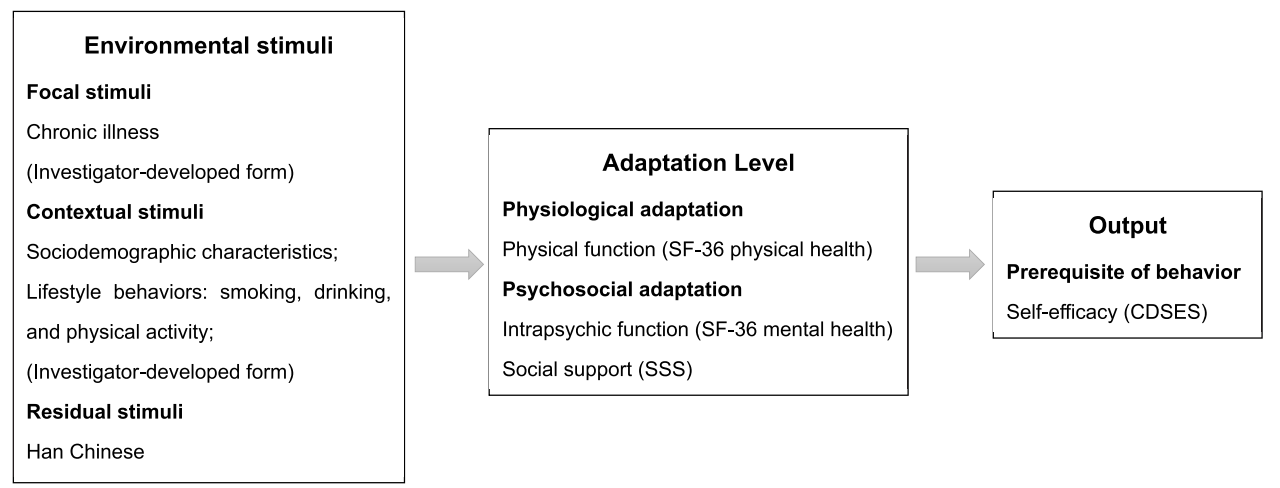

Figure I Hypothesized framework for the measurement of stimuli, adaptation level, and output.

Abbreviations: SF-36, Medical Outcomes Study Short-Form Health Survey; SSS, Social Support Scale; CDSES, Chronic Disease Self-Efficacy Scales (Chinese version).

hypertension (HTN), fluency in Mandarin Chinese, able to communicate verbally, and has no mental disorder.

Identification of MetS patients was based on an ethnicspecific MetS criterion proposed by the International Diabetes Federation (IDF) in $2005 .{ }^{28}$ A positive diagnosis for MetS was established if the abdominal obesity was associated with any other two risk factors: (1) abdominal obesity: waist circumference (WC) $\geq 90 \mathrm{~cm}$ for males and $\geq 80 \mathrm{~cm}$ for females; (2) serum glucose: fasting plasma glucose $(\mathrm{FPG}) \geq 5.6 \mathrm{mmol} / \mathrm{L}$ or previously diagnosed diabetes with medical treatment; (3) hypertension: systolic blood pressure $(\mathrm{SBP}) \geq 130 \mathrm{mmHg}$ and/or diastolic blood pressure $(\mathrm{DBP}) \geq 85 \mathrm{mmHg}$, or medical treatment of previously diagnosed hypertension; (4) triglycerides (TG) $>1.70 \mathrm{mmol} / \mathrm{L}$ or treatment; (5) plasma high-density lipoprotein cholesterol (HDL-C) $<1.03 \mathrm{mmol} / \mathrm{L}$ for male and $<1.29 \mathrm{mmol} / \mathrm{L}$ for female, or treatment.

\section{Data Collection}

Screening of MetS patients and questionnaire distribution were conducted by three nursing graduate students. They used a convenient sampling method to approach participants $(\mathrm{N}=450)$. Participants with metabolic problems were selected from the digital health records suggested by family physicians who provide them with care. The researchers thereby introduced to them the objectives of this study for recruitment through telephone calls. A total of 381 participants agreed to do the blood test for detecting MetS. Overnight fasting blood specimens were obtained for measuring the metabolic indexes. Blood specimens were taken to community clinics and analyzed in a tertiary hospital (certificated by Joint Commission International) in China. Blood pressure and anthropometric measurements (height, weight, and waist circumference) were obtained by trained nurses using standard protocols and techniques. A total of 285 participants met the criteria for MetS, and 192 participants were approached for a questionnaire survey. Investigators gave a few instructions for filling questionnaires but did not guide the participants. The self-report paper survey took about 30-40 minutes to complete.

\section{Ethical Considerations}

Approval for this study was obtained from the Ethics Committee of Sir Run Run Shaw Hospital, Zhejiang University School of Medicine (20,161,212-1). The purpose and procedures of the study were explained to all respondents before data collection. Written consent from every participant was obtained. The investigation conforms with principles outlined in the Declaration of Helsinki.

\section{Instruments}

An investigator-developed form was used to collect data on patient demographic characteristics (age, sex, marriage status, religion, education level, job, and family income), smoking, drinking, physical activity, medical history, and treatment history. These data were collected for environmental stimuli observation.

Indexes for sample screening and assessment of MetS potential risks were based on the following variables: WC, FPG, BP, TG, HDL-C, history of HTN, history of T2DM, and history of hyperlipidemia (HLP). These physiological indexes were examined to identify the severity of illness.

The adaptation level for individuals was evaluated using the Chinese version of Medical Outcomes Study Short-Form Health Survey (SF-36). SF-36 is a widely used instrument with eight health domains including 
physical functioning (PF), role-physical (RP), bodily pain (BP), general health (GH), vitality (VT), social functioning (SF), role-emotional (RE), and mental health $(\mathrm{MH})$. PF, $\mathrm{RP}, \mathrm{BP}$, and GH highlighted the physical component of adaptation. The VT, SF, RE, and MH were considered as the psychological component of adaptation. Cronbach's alpha for subscales ranged from 0.72 to $0.88 .^{29}$

The 10-item Social Support Scale (SSS) developed by Xiao in 1986 and modified in 1994 within the Chinese culture, measured the objective support, subjective support, and use of support. ${ }^{30}$ Cronbach's alpha coefficient of 0.89 signified adequate reliability and validity. ${ }^{31}$ Higher scores suggested better social support. The focus of this study was to identify the potential adaptive modes, therefore, social support was included in psychosocial adaptation assessment.

The 6-item and 10-point Chinese version of Chronic Disease Self-Efficacy Scale (CDSES) was adopted for self-efficacy assessment. It measured individual confidence in symptom control, role function, emotional functioning, and communication with physicians. ${ }^{32}$ The CDSES with sound psychometric properties has widely been used in Chinese adults with various chronic diseases. ${ }^{24,31}$ The CDSES score indicates the mean for the six items, therefore, a higher score implies higher selfefficacy in managing chronic illness. The mean score for the Chinese version of CDSES at seven and above signifies adequate self-efficacy. ${ }^{33}$ In this study, self-efficacy was hypothesized as a prerequisite of behavior to display individual capacity in handling health problems.

\section{Data Analysis}

Data from a different study on self-efficacy among community-dwelling patients with chronic illness was used to obtain 0.3 a correction coefficient. ${ }^{31}$ A minimum total of 115 participants would be adequate to detect an effect size of 0.3 with a power of $0.95 .{ }^{34}$ It was tested by G-power 3.1 under multiple predictors for the regression model. SPSS version 22.0 was used for data analysis. Descriptive analysis was performed to determine the mean and standard deviation (SD) for continuous variables and frequency/percentages for categorical variables. The correlates of scale scores were determined using Spearman's analysis. Furthermore, categorical variables were converted to dummy variables. Multiple linear regression with the enter method was applied to identify the association between stimuli and adaptation level using participants' characteristics data, HRQOL, and social support. Binary logistics regression with the enter method was used to estimate the adaptation level that significantly correlated with behavioral output determined by selfefficacy. Statistical significance was determined by $P$-value $(p=0.05)$.

\section{Results \\ Participants' Characteristics}

The essential characteristics of the participants describing the environmental (focal, contextual, and residual) stimuli are summarized in Table 1. A total of 144 MetS patients from the Chinese Han population were recruited. They had an average age of 61.42 years ranging from 36 to 82 years. Most participants were married (97.90\%), female (65.97\%), and had an elementary school education (77.78\%). About $52.78 \%$ of participants had no religious beliefs. As for the physical activity, $79.86 \%$ of participants always took a walk whereby $66.00 \%$ of them spent one quarter to one hour every time, and $52.80 \%$ exercised more than 5 times per week. Through the BMI test, $54.86 \%$ of participants were overweight, and $14.58 \%$ were obese. Following the IDF 2005,43 out of the 144 participants had three types of cardiometabolic risks, 62 had four types, and 39 had five types. All the participants showed abdominal obesity. The average WC mean was $94.35 \mathrm{~kg} / \mathrm{m}^{2}$ and $87.82 \mathrm{~kg} / \mathrm{m}^{2}$ for males and females respectively. The estimated prevalence of abnormal BP, FPG, BP, and HDL-C was $89.60 \%$, $92.40 \%, 63.20 \%$, and $48.60 \%$ respectively.

\section{Predictors for Adaptation Level Tested by Environmental Stimuli}

Multiple linear regression was used to investigate the relationship between environmental stimuli and adaptation levels employing the enter method. The stimuli showed physiological adaptation variance at $23.7 \%$ (adjust $\mathrm{R}^{2}=0.106, \quad \mathrm{~F}=1.808, \quad p=0.025$ ), and $26.2 \%$ (adjust $\left.\mathrm{R}^{2}=0.135, \mathrm{~F}=2.058, p=0.008\right)$ psychosocial adaptation variance. Age and education level were identified as significant correlates of physical and intrapsychic function. No variable was identified as a significant correlate of social support. The findings demonstrated that older patients frequently suffered from impoverished physical $(\mathrm{B}=-0.301, p=0.001)$ and mental health $(\mathrm{B}=-0.247$, $p=0.007)$. Patients with middle school education experience had a higher impoverished physical $(B=-0.215$, $p=0.018)$ and mental health $(\mathrm{B}=-0.256, p=0.004)$ compared with those with elementary education. 
Table I Demographic Characteristics of Participants and Self-Efficacy $(N=\mid 44)$

\begin{tabular}{|c|c|c|c|c|}
\hline Demographics & $\mathbf{N}(\%)$ & Mean (SD) & F Value & $\mathbf{P}$ \\
\hline \multicolumn{5}{|l|}{ Sex } \\
\hline Male & $49(34.03)$ & $7.34(1.40)$ & 0.014 & 0.905 \\
\hline Female & $95(65.97)$ & $7.38(1.69)$ & & \\
\hline \multicolumn{5}{|l|}{ Religion } \\
\hline No religion & $76(52.78)$ & 7.21 (1.59) & $\mathrm{I} .46 \mathrm{I}$ & 0.236 \\
\hline Buddhist & $65(45.14)$ & $7.59(1.60)$ & & \\
\hline Christian & $3(2.08)$ & $6.50(1.09)$ & & \\
\hline \multicolumn{5}{|l|}{ Education level } \\
\hline Primary school & $112(77.78)$ & $7.42(1.55)$ & 0.246 & 0.782 \\
\hline Middle school & $26(18.06)$ & $7.17(1.85)$ & & \\
\hline High school & $6(4.17)$ & $7.33(1.37)$ & & \\
\hline \multicolumn{5}{|l|}{$\begin{array}{l}\text { Family income } \\
\qquad \text { (per month, CNY) }\end{array}$} \\
\hline$<4000$ (570 USD) & 71 (49.3I) & $7.12(1.59)$ & 3.478 & 0.018 \\
\hline 4000-10,000 (I430 USD) & $59(40.97)$ & $7.40(1.04)$ & & \\
\hline $10,000-15,000$ (2।40 USD) & $6(4.17)$ & $9.00(1.04)$ & & \\
\hline$>15,000(2 \mid 40$ USD $)$ & $8(5.55)$ & $8.14(1.24)$ & & \\
\hline \multicolumn{5}{|l|}{ Job } \\
\hline Retirement & $52(36.11)$ & $7.30(1.53)$ & 4.87 & 0.003 \\
\hline Farmer & $54(37.50)$ & $7.08(1.63)$ & & \\
\hline Employed & $18(12.50)$ & $7.11(1.25)$ & & \\
\hline Housewife/freelance & $20(13.89)$ & $8.56(1.50)$ & & \\
\hline \multicolumn{5}{|l|}{ Smoking } \\
\hline Yes & $19(13.19)$ & $7.06(1.58)$ & 0.772 & 0.464 \\
\hline Stopped & $18(12.50)$ & $7.71(1.21)$ & & \\
\hline No & $107(74.31)$ & $7.37(1.65)$ & & \\
\hline \multicolumn{5}{|l|}{ Drinking } \\
\hline Yes & $28(19.44)$ & $7.33(1.52)$ & 0.152 & 0.859 \\
\hline Stopped & $7(4.86)$ & $7.69(1.48)$ & & \\
\hline No & $109(75.69)$ & $7.36(1.63)$ & & \\
\hline \multicolumn{5}{|l|}{ Physical activity (per week) } \\
\hline 0 time & $19(13.19)$ & $7.47(1.4 \mathrm{I})$ & 2.220 & 0.089 \\
\hline $\mathrm{I}-2$ times & $18(12.50)$ & $6.60(1.22)$ & & \\
\hline $3-4$ times & 31 (2I.53) & $7.80(1.69)$ & & \\
\hline More than 5 times & $76(52.78)$ & $7.35(1.63)$ & & \\
\hline
\end{tabular}

Additionally, family income was related to physical function (Table 2).

\section{Prerequisite for Behavior Estimated by Adaptation Level}

Spearman's analysis (Table 3) showed that HRQOL and social support were positively associated with self-efficacy. The correlation coefficient of HRQOL and self-efficacy ranged from 0.231 to $0.571(p<0.01)$. The correlation coefficient for perceived social support and self-efficacy was 0.181 $(p<0.05)$. Using CDSES, 77 (53.47\%) participants had adequate self-efficacy. As shown in Table 4, binary logistic regression was performed to estimate the self-efficacy level by HRQOL and social support with an enter method after controlling the variables (family income and job that displayed in Table 1). The associations between the variables were tested by the resulting model (Chi-square 48.008, $p<0.001$ ) with a Nagelkerke $R^{2}$ at 0.379 . The findings showed a percentage 
Table 2 Summary of Multiple Regression Analysis of Sociodemographic Characteristics and Health-Related Quality of Life

\begin{tabular}{|c|c|c|c|c|}
\hline \multirow[t]{2}{*}{ Variables } & \multicolumn{2}{|c|}{$\begin{array}{l}\text { Physical } \\
\text { Function }\end{array}$} & \multicolumn{2}{|c|}{$\begin{array}{l}\text { Intrapsychic } \\
\text { Function }\end{array}$} \\
\hline & Beta & $\mathbf{P}$ & Beta & $\mathbf{P}$ \\
\hline Number of comorbidities & -.124 & .202 & -.159 & .098 \\
\hline $\begin{array}{l}\text { Number of abnormal metabolic } \\
\text { components }\end{array}$ & .005 & .958 & -.035 & .705 \\
\hline Age & -.301 & .001 & -.247 & .007 \\
\hline Female versus Male & -.023 & .870 & .026 & .854 \\
\hline Buddhist versus No & .003 & .971 & -.018 & .838 \\
\hline Christian versus No religion & .075 & .392 & -.012 & .889 \\
\hline Middle school versus Primary school & -.215 & .018 & -.256 & .004 \\
\hline High school versus Primary school & -.106 & .240 & -.071 & .427 \\
\hline $4,000-10,000$ versus less than $4,000 Y$ & -.014 & .903 & -.117 & .296 \\
\hline $10,000-15,000$ versus less than $4,000 Y$ & -.088 & .375 & .042 & .663 \\
\hline More than 15,000 versus less than $4,000 Y$ & .201 & .039 & .133 & .161 \\
\hline Farmer versus retirement & -.048 & .696 & -.156 & .196 \\
\hline Employed versus retirement & -.169 & .076 & -.108 & .245 \\
\hline Housewife/freelance versus retirement & .066 & .541 & .066 & .530 \\
\hline Quit smoking versus No smoking & .102 & .411 & .198 & .104 \\
\hline Smoking versus No smoking & .110 & .350 & .102 & .380 \\
\hline Quit drinking versus No drinking & .082 & .480 & -.135 & .239 \\
\hline Drinking versus No drinking & -.016 & .891 & .009 & .939 \\
\hline $1-2$ times versus 0 time & -.079 & .480 & -.177 & .112 \\
\hline $3-4$ times versus 0 time & .137 & .307 & -.061 & .643 \\
\hline More than versus 0 time & .115 & .434 & -.070 & .628 \\
\hline$R^{2}$ & $0.237 *$ & & $0.262^{*}$ & \\
\hline
\end{tabular}

Note: *Significant $R^{2}$ changes from the base model to the null model.

classification accuracy of $76.40 \%$, the specificity rate was $70.10 \%$, and the sensitivity rate was $81.80 \%$. Among the HRQOL and social support aspects, vitality (OR: 1.051, 95\% CI: $1.001-1.104, p=0.046)$ and social functioning (OR: 1.044, 95\% CI: $1.007-1.083, p=0.020)$ were significant correlates for self-efficacy.

\section{Discussion}

Following the MRT-ACI, the study findings illustrate that adaptation level is a combined representation of physiological and psychosocial factors. The adaptation level implies the influence of stimuli and predicts healthpromoting behaviors for illness management.

As noted in the RAM, the stimuli assessment involves identifying internal and external resources of the adaptation level. In this study, the MetS and fundamental diseases (such as HTN and DM) were regarded as the focal stimuli and failed to predict the adaptation level. The diagnosis of illness is a common stimulus affecting
Table 3 Summary of the Correlation Analysis of Adaptation Level and Output of Behavior

\begin{tabular}{|l|l|l|l|}
\hline \multirow{2}{*}{ Variable } & Mean (SD) & \multicolumn{2}{|l|}{ Self-Efficacy } \\
\cline { 3 - 4 } & & $\boldsymbol{r}$ & $\boldsymbol{P}$ \\
\hline Health-related quality of life & & & \\
HRQOL-PF & $84.38 \pm 19.08$ & 0.383 & 0.000 \\
HRQOL-RP & $69.97 \pm 42.39$ & 0.231 & 0.005 \\
HRQOL-BP & $81.23 \pm 19.87$ & 0.285 & 0.001 \\
HRQOL-GH & $52.83 \pm 20.50$ & 0.396 & 0.000 \\
HRQOL-VT & $73.47 \pm 16.41$ & 0.571 & 0.000 \\
HRQOL-SF & $96.70 \pm 16.06$ & 0.413 & 0.000 \\
HRQOL-RE & $80.09 \pm 3.05$ & 0.236 & 0.004 \\
HRQOL-MH & $75.19 \pm 15.91$ & 0.443 & 0.000 \\
HRQOL-HT & $46.18 \pm 19.68$ & 0.187 & 0.025 \\
\hline Social support & & & \\
Objective support & $9.51 \pm 3.33$ & 0.086 & 0.306 \\
Subjective support & $23.52 \pm 4.35$ & 0.181 & 0.030 \\
Use of support & $6.79 \pm 1.71$ & -0.039 & 0.640 \\
\hline
\end{tabular}

Abbreviations: $\mathrm{HRQOL}$, health-related quality of life; PF, physical functioning; RP, role-physical; BP, bodily pain; GH, general health; VT, vitality; SF, social functioning; $\mathrm{RE}$, role-emotional; $\mathrm{MH}$, mental health; $\mathrm{HT}$, health transition.

adaptation, however, significant symptoms and disabilities caused by the illness may easily affect individual adaptation level. ${ }^{13,35}$ Lack of knowledge on MetS by the participants may also make them unable to perceive illness impact. Illness perception represents a cognitive or emotional coping process for a health threat and directly influences HRQOL and self-efficacy. ${ }^{19}$ Absence of MetS diagnosis calls for an urgent and early screening programs for the Chinese community-dwelling in the suburban areas. Determining the statistics for MetS components is also necessary for the early management of medication therapy to identify its component conditions. This is beneficial to prevent CVD and T2DM.

Demographic characteristics and lifestyles were measured as contextual stimuli, and are similar to personal and behavioral health factors defined in other studies. ${ }^{25,33}$ Preliminary results from this study suggest that selected personal factors were associated with the adaptation level. Increasing age would, therefore, lead to low HRQOL. This will directly influence physiological and psychosocial adaptation and indirectly affect self-efficacy. Additionally, the effects of educational attainment and family income on an individual's adaptation level were examined. However, further inquiry is required to explore the role of contextual stimuli in illness adaptation. Lifestyle behaviors including smoking, drinking, and physical activity could not predict physiological adaptation in this study. The residents in 
Table 4 Summary of the Binary Logistic Analysis of Adaptation Level for Output of Behavior

\begin{tabular}{|l|l|l|l|l|l|l|}
\hline & B & S.E. & Wald & $\boldsymbol{P}$ & Exp(B) & $\mathbf{9 5 \%}$ Cl \\
\hline Objective support & .031 & .076 & .162 & .687 & 1.031 & {$[0.888,1.197]$} \\
Subjective support & .058 & .061 & .911 & .340 & 1.060 & {$[0.941,1.194]$} \\
Use of support & -.089 & .130 & .470 & .493 & .915 & {$[0.708,1.181]$} \\
HRQOL-PF & -.017 & .016 & 1.099 & .294 & .983 & {$[0.952,1.015]$} \\
HRQOL-RP & .003 & .007 & .129 & .719 & 1.003 & {$[0.989,1.016]$} \\
HRQOL-BP & -.008 & .013 & .421 & .516 & .992 & {$[0.967,1.017]$} \\
HRQOL-GH & .012 & .014 & .825 & .364 & 1.012 & {$[0.986,1.040]$} \\
HRQOL-VT & .050 & .025 & 3.973 & .046 & 1.051 & {$[1.001,1.104]$} \\
HRQOL-SF & .043 & .019 & 5.448 & .020 & 1.044 & {$[1.007,1.083]$} \\
HRQOL-RE & .002 & .008 & .045 & .832 & 1.002 & {$[0.985,1.018]$} \\
HRQOL-MH & .010 & .023 & .172 & .679 & 1.010 & {$[0.965,1.057]$} \\
HRQOL-HT & .006 & .012 & .246 & .620 & 1.006 & {$[0.982,1.030]$} \\
Constant & -8.692 & 2.224 & 15.276 & .000 & .000 & \\
\hline
\end{tabular}

Abbreviations: HRQOL, health-related quality of life; PF, physical functioning; RP, role-physical; BP, bodily pain; GH, general health; VT, vitality; SF, social functioning; RE, role-emotional; $\mathrm{MH}$, mental health; $\mathrm{HT}$, health transition, $\mathrm{Cl}$, confidence interval.

targeted communities possibly share similar lifestyles and health behaviors as reported in the data (Table 1). Our results showed that no association existed between demographics and social support, this is in contrast with previous studies. ${ }^{21,31}$ A report by Karimy et $\mathrm{al}^{21}$ found that diabetic patients with higher education levels would have higher levels of social support. The main population in the suburban study area were residents who with low education level, low socioeconomic status, and low health literacy. This led to the high homogeneity of the characteristics of participants in this study. Therefore, future studies should recruit participants from varying living environments, education levels, and social-economic status to explore their effects as contextual stimuli.

The HRQOL was measured to test the hypothesis that behavior could be reflected by adaptation level, ${ }^{13}$ this complied with the essence for adaptation. ${ }^{23,36}$ Previous findings confirmed that higher self-efficacy is associated with better HRQOL, and their assessment tools were conceptually related. ${ }^{24}$ Similarly, based on the partial hypothesis (Figure 1), it was perceived that social support is positively associated with self-efficacy, this concurs with other related studies. ${ }^{13,17,37}$ Social functioning and vitality were significant self-efficacy predictors in chronic health conditions. The finding gives a better understanding of a bidirectional relationship between individual capacities and behavioral preconditions. ${ }^{17}$ However, further studies on quantifying the relationships between adaptation level and behavioral response are required.
Self-efficacy was assumed to act as a guide for nursing judgment on adaptive behavior, because it significantly predicts effective self-management behaviors. ${ }^{25,27,33}$ A nurseled health promotion program enhancing self-efficacy in individuals showed reduced cardiometabolic components in older adults. ${ }^{27} \mathrm{~A}$ report by Mohebi et al ${ }^{38}$ found that selfefficacy is associated with individual health literacy, diseasespecific knowledge, personal persistence, and high expectation for desirable outcomes. Similarly, other reports on selfefficacy indicate that confidence required when developing a behavior to achieve an expected goal. ${ }^{19,39}$ The adaptation level is related to capacity levels when coping with changing circumstances. ${ }^{15,19}$ Interventions for MetS self-management would be designed to improve the individuals' inner resources and coping capacity.

The operationalization of adaptation level and prospects for further studies on nursing practice have been highlighted from this study. Environmental stimuli determine the adaptation level, this indicates that extending the inner and external resources for individuals is important for MetS management. Evaluating social functioning, assessing illness severity, and exploring illness perceptions in patients lay the foundations for promoting their integrity within the four adaptive modes (physical, self-concept, role function, and interdependence modes). ${ }^{9,13,19}$ Previous studies demonstrate that unhealthy lifestyles are risk factors for MetS, whereas, health-impairing behaviors are obstacles for MetS management. ${ }^{40-42}$ Lifestyle modifications and self-efficacy improvement, for example, weight management, dietary control, enhanced physical activity, quitting smoking, and decreased alcohol intake, are important interventional tasks for MetS populations. ${ }^{9,11,42}$ 
Therefore, nursing interventions for improved adaptation levels must be implemented in MetS patients.

\section{Limitations}

This survey was limited by observational and cross-sectional study design using convenient sampling. More definitive evidence that highlights the associations between selected variables for concept clarification (stimuli, adaptation level, and output) should be generated from experimental and qualitative studies. Secondly, the recruited participants were not adequate in developing a structured equation model. Future studies may test the theoretical assumption of MRT-ACI in MetS patients and determine the mediating factors for the adaptation process. Thirdly, this study did not incorporate nutrient intake investigation. Information on nutrition and dietary quality changes are recommended to support the cardiometabolic risk-related studies.

\section{Conclusion}

The preliminary finding supports the proposal that the adaptation level can be regarded as a response to environmental stimuli and plays an important role in triggering the output of adaptive behaviors. We recommend that individuals' adaptation levels should be measured when developing tailored health promotion interventions. Future prospective studies are required to explore the effect of adaptive behaviors on MetS-related self-management.

\section{Acknowledgments}

We appreciate all the patients and their family members who involved in this study. We thank the family physicians in the community clinics for their help.

\section{Funding}

This work was supported by the Medical Health Science and Technology Project of Zhejiang Province (grant number WKJ-1925) and Department of Health of Zhejiang Province (grant number 2019ZD034). The funders had no involvements in study design, data collection, results interpretation, decision to publish or preparation of the manuscript.

\section{Disclosure}

The authors report no conflicts of interest in this work.

\section{References}

1. Benjamin EJ, Muntner P, Alonso A, et al. Heart disease and stroke statistics-2019 Update: a report from the American heart association. Circulation. 2019;139(10):e56-e66.
2. Huang J, Huang JLW, Withers M, et al. Prevalence of metabolic syndrome in Chinese women and men: a systematic review and metaanalysis of data from 734511 individuals. Lancet. 2018;392:S14.

3. Li W, Song F, Wang X, et al. Prevalence of metabolic syndrome among middle-aged and elderly adults in China: current status and temporal trends. Ann Med. 2018;50(4):345-353. doi:10.1080/ 07853890.2018 .1464202

4. Wang X, Howell D, Tang L, Shao J, Ye Z. Comparative study on prevalence of metabolic syndrome based on three criteria among adults in Zhejiang province, China: an observational study. BMJ Open. 2020;10(4):e035216. doi:10.1136/bmjopen-2019-035216

5. Jing Y, Hong T, Bi Y, et al. Prevalence, treatment patterns and control rates of metabolic syndrome in a Chinese diabetic population: China cardiometabolic registries 3B study. J Diabetes Investig. 2018;9 (4):789-798. doi:10.1111/jdi.12785

6. Dunkley AJ, Charles K, Gray LJ, et al. Effectiveness of interventions for reducing diabetes and cardiovascular disease risk in people with metabolic syndrome: systematic review and mixed treatment comparison meta-analysis. Diabetes Obes Metab. 2012;14(7):616-625.

7. Ambrosio L, Senosiain Garcia JM, Riverol Fernandez M, et al. Living with chronic illness in adults: a concept analysis. J Clin Nurs. 2015;24(17-18):2357-2367. doi:10.1111/jocn.12827

8. Samson A, Siam H. Adapting to major chronic illness: a proposal for a comprehensive task-model approach. Patient Educ Couns. 2008;70 (3):426-429. doi:10.1016/j.pec.2007.10.018

9. Shahin W, Kennedy GA, Stupans I. The impact of personal and cultural beliefs on medication adherence of patients with chronic illnesses: a systematic review. Patient Prefer Adherence. 2019;13:1019-1035. doi:10.2147/PPA.S212046

10. Brauer P, Royall D, Li A, et al. Nutrient intake and dietary quality changes within a personalized lifestyle intervention program for metabolic syndrome in primary care. Appl Physiol Nutr Metab. 2019;44(12):1297-1304. doi:10.1139/apnm-2019-0070

11. Lin CH, Chiang SL, Tzeng WC, Chiang LC. Systematic review of impact of lifestyle-modification programs on metabolic risks and patient-reported outcomes in adults with metabolic syndrome. Worldviews Evid Based Nurs. 2014;11(6):361-368. doi:10.1111/ wvn. 12069

12. Sister Callista R. The Roy Adaptation Model. Third ed. New Jersey: Pearson Education, Inc; 2009.

13. Pollock SE. Adaptation to chronic illness: a program of research for testing nursing theory. Nurs Sci Q. 1993;6(2):86-92. doi:10.1177/ 089431849300600208

14. Helson H. Current trends and issues in adaptation-level theory. $\mathrm{Am}$ Psychol. 1964;19(1):26-38. doi:10.1037/h0040013

15. DeSanto-Madeya S, Fawcett J. Toward understanding and measuring adaptation level in the context of the Roy adaptation model. Nurs Sci Q. 2009;22(4):355-359. doi:10.1177/0894318409344753

16. Barone SH, Roy CL, Frederickson KC. Instruments used in Roy adaptation model-based research: review, critique, and future directions. Nurs Sci Q. 2008;21(4):353-362. doi:10.1177/0894318408323491

17. Bowen PG, Clay OJ, Lee LT, et al. Associations of social support and self-efficacy with quality of life in older adults with diabetes. $J$ Gerontol Nurs. 2015;41(12):21-29; quiz 30-21. doi:10.3928/ 00989134-20151008-44

18. Selzler AM, Habash R, Robson L, et al. Self-efficacy and health-related quality of life in chronic obstructive pulmonary disease: a meta-analysis. Patient Educ Couns. 2019.

19. Knowles SR, Apputhurai P, O'Brien CL, et al. Exploring the relationships between illness perceptions, self-efficacy, coping strategies, psychological distress and quality of life in a cohort of adults with diabetes mellitus. Psychol Health Med. 2020;25(2):214-228. doi:10.1080/13548506.2019.1695865

20. Bishop M. Quality of life and psychosocial adaptation to chronic illness and disability. Rehabil Couns Bull. 2005;48(4):219-231. doi: $10.1177 / 00343552050480040301$ 
21. Karimy M, Koohestani HR, Araban M. The association between attitude, self-efficacy, and social support and adherence to diabetes self-care behavior. Diabetol Metab Syndr. 2018;10:86. doi:10.1186/ s13098-018-0386-6

22. Uchino BN, Bowen K, Carlisle M, Birmingham W. Psychological pathways linking social support to health outcomes: a visit with the "ghosts" of research past, present, and future. Soc Sci Med. 2012;74 (7):949-957. doi:10.1016/j.socscimed.2011.11.023

23. Londono Y, McMillan DE. Psychosocial adaptation: an evolutionary concept analysis exploring a common multidisciplinary language. $J$ Adv Nurs. 2015;71(11):2504-2519. doi:10.1111/jan. 12723

24. Chow SK, Wong FK. The reliability and validity of the Chinese version of the short-form chronic disease self-efficacy scales for older adults. J Clin Nurs. 2014;23(7-8):1095-1104. doi:10.1111/jocn. 12298

25. Ji M, Ren D, Dunbar-Jacob J, Gary-Webb TL, Erlen JA. Correlates of self-management behaviors, glycemic control and metabolic syndrome in patients with type 2 diabetes. Nurs Res. 2019.

26. Brady TJ, Murphy L, O’Colmain BJ, et al. A meta-analysis of health status, health behaviors, and health care utilization outcomes of the chronic disease self-management program. Prev Chronic Dis. 2013;10:120112. doi:10.5888/pcd10.120112

27. Wu MP, Wu SV, Lee MC, et al. Health-promotion interventions enhance and maintain self-efficacy for adults at cardiometabolic risk: a randomized controlled trial. Arch Gerontol Geriatr. 2019;82:61-66. doi:10.1016/j.archger.2019.01.009

28. Alberti KGMM, Zimmet P, Shaw J. The metabolic syndrome-a new worldwide definition. Lancet. 2005;366(9491):1059-1062. doi:10.10 16/S0140-6736(05)67402-8

29. Li L, Wang H, Shen Y. Development and psychometric tests of a Chinese version of the SF-36 health survey scale. Chin J Prev Med. 2002;36(2):109-114.

30. Xiao S. The theoretical framework and application of social support scale. J Clin Psychol Med. 1994;4(2):98-100.

31. Wang L, Liu L, Liu S, An Q, Yang X. The relationship between social support and self-efficacy among chronic patients in community. Chin Nurs Manag. 2011;11(8):69-70.

32. Lorig KR, Sobel DS, Ritter PL, Laurent D, Hobbs M. Effect of a self-management program on patients with chronic disease. Eff Clin Pract. 2001;4(6):256-262.
33. Zhang L, Liu X, Ning YH, Gu R. The relevance study of self-efficacy and self-management behaviors of hypertensive older people in the community. Chin J Gerontol. 2011;6(31):2286-2288.

34. Karaiskos I, Giamarellou H. Carbapenem-sparing strategies for ESBL producers: when and how. Antibiotics. 2020;9(2). doi:10. 3390/antibiotics 9020090

35. Qiu R, Schick-Makaroff K, Tang L, et al. Chinese hospitalized cardiovascular patients' attitudes towards self-management: a qualitative study. Patient Prefer Adher. 2020;14:287-300. doi:10.21 47/PPA.S236348

36. Livneh H. Psychosocial adaptation to chronic illness and disability. Rehabil Couns Bull. 2001;44(3):151-160. doi:10.1177/003435520 104400305

37. Xiao Y, Wang H, Zhang T, Ren X. Psychosocial predictors of physical activity and health-related quality of life among Shanghai working adults. Health Qual Life Outcomes. 2019;17(1):72. doi:10.1186/ s12955-019-1145-6

38. Mohebi S, Azadbakht L, Feizi A, Sharifirad G, Hozori M. Predicting of perceived self efficacy in the amount of macronutrients intake in women with metabolic syndrome - 2012. J Educ Health Promot. 2014;3:21. doi:10.4103/2277-9531.127608

39. Zhang P, Xing FM, Li CZ, Wang FL, Zhang XL. Effects of a nurse-led transitional care programme on readmission, self-efficacy to implement health-promoting behaviours, functional status and life quality among Chinese patients with coronary artery disease: A randomised controlled trial. J Clin Nurs. 2018;27(5-6):969-979. doi:10.1111/jocn. 14064

40. Wu TT, Chen IJ, Cho SL, Chiou AF. The relationship between health-promoting behaviors and metabolic syndrome in community-dwelling older adults. Biol Res Nurs. 2016;18(5):549-557. doi:10.1177/1099800416655882

41. Chang SH, Chen MC, Chien NH, Lin HF. Effectiveness of community-based exercise intervention programme in obese adults with metabolic syndrome. J Clin Nurs. 2016;25(17-18):2579-2589. doi:10.1111/jocn.13301

42. Lee G, Yang SJ, Chee YK. Assessment of healthy behaviors for metabolic syndrome among Korean adults: a modified information-motivation-behavioral skills with psychological distress. BMC Public Health. 2016;16:518. doi:10.1186/s12889-016-3185-8
Patient Preference and Adherence

\section{Publish your work in this journal}

Patient Preference and Adherence is an international, peer-reviewed, open access journal that focuses on the growing importance of patient preference and adherence throughout the therapeutic continuum. Patient satisfaction, acceptability, quality of life, compliance, persistence and their role in developing new therapeutic modalities and compounds to optimize clinical outcomes for existing disease states are major areas of interest for the journal. This journal has been accepted for indexing on PubMed Central. The manuscript management system is completely online and includes a very quick and fair peer-review system, which is all easy to use. Visit http:// www.dovepress.com/testimonials.php to read real quotes from published authors. 